\title{
Modifikasi Angklung Sunda
}

\author{
Dinda Satya Upaja Budi ${ }^{1}$ \\ Program Studi Angklung dan Musik Bambu, ISBI Bandung
}

\begin{abstract}
ABSTRAK
Artikel ini menguraikan hasil modifikasi terhadap angklung yang telah dilakukan oleh para seniman Sunda. Metode lintas disiplin dengan pendekatan organologis digunakan dalam penelitian ini. Data diperoleh dengan pengamatan terhadap proses modifikasi yang telah dilakukan pada angklung. Berdasarkan penelitian dapat disimpulkan bahwa upaya-upaya modifikasi yang dilakukan terhadap angklung merupakan langkah pengembangan yang meliputi tangga nada, teknik permainan, bahan, bentuk, serta ornamen atau aksesoris. Modifikasi ini merupakan upaya termutakhir yang telah berhasil dilakukan oleh para seniman Sunda sampai saat ini.
\end{abstract}

Kata kunci: angklung; musik bambu; musik Sunda

\begin{abstract}
Modification of Sundanese Angklung. This article describes the modification of angklung that has been done by Sundanese artists. The interdisciplinary method with the organological approach was used in this study. Data is obtained by observing the modification process that has been carried out on angklung. Based on the research it can be concluded that the modification efforts made on angklung are a development step which includes scales, game techniques, materials, shapes, and ornaments or accessories. This modification is the most recent effort that has been successfully carried out by Sundanese artists until today.
\end{abstract}

Keywords: angklung; bamboo music; Sundanese music

\section{Pendahuluan}

Perkembangan ilmu pengetahuan dan teknologi, khususnya teknologi informasi, sangat terasa dampaknya terhadap eksistensi kesenian tradisional. Sebagian besar kesenian tradisional semakin tersisih, bahkan ada sebagian yang sama sekali tidak mendapat perhatian, baik dari para pelaku sendiri maupun dari masyarakat pendukungnya. Angklung sebagai salah satu produk kesenian tradisional tidak lepas dari pengaruh kondisi tersebut. Meskipun demikian, terdapat situasi dan kondisi yang cukup memberi peluang atau upaya untuk mempertahankan atau mengembangkan angklung, terutama setelah Angklung Indonesia dikukuhkan UNESCO sebagai salah satu representative list of the intangible world culture heritage (warisan budaya tak benda milik dunia) pada tanggal 16 November 2010. Dapat dikatakan bahwa angklung merupakan salah satu seni tradisi yang dapat mendunia tanpa meninggalkan nilai dan ciri tradisi budayanya (Musthofa, n.d.: 137). Hukum kekayaan intelektual menganggap bahwa hukum properti budaya menanamkan gagasan kepemilikan kelompok (Halliburton \& Aragon, 2012: 270).

Sejak pengukuhan tersebut, keberadaan angklung seakan tidak lagi mengkhawatirkan. Berbagai kegiatan yang melibatkan angklung terus mengalir, bahkan seolah tidak terbendung. Berbagai kalangan begitu giat menyelenggarakan bermacam-macam kegiatan dalam periode yang berdekatan, baik secara insidental maupun secara berkala, baik dalam event yang melibatkan orang

1 Alamat korespondensi: Prodi Angklung dan Musik Bambu, Jurusan Musik, Fakultas Seni Pertunjukan ISBI Bandung Jln. Buahbatu No. 212 Bandung 40265. HP. +62 81321369866. E-mail: dindasatya@gmail.com. 
dalam jumlah kecil maupun besar atau kolosal sampai ribuan orang. Pemerintah pun sebagai fasilitator, khususnya pemerintah daerah, tidak bisa melayani semua kegiatan yang diajukan oleh para penggiat angklung. Sementara itu, masyarakat tetap menuntut agar angklung sebagai asset budaya perlu ditangani secara serius dan segera, karena sebagai aset budaya bangsa, angklung telah memiliki peran yang berarti bagi bangsa maupun bagi masyarakat pendukungnya.

Sebagaimana diketahui, agak sulit untuk menelusuri siapa yang membuat, kapan, dan di mana tepatnya angklung ini dibuat. Namun dapat diyakini bahwa angklung sudah ada sejak ratusan bahkan mungkin ribuan tahun yang lalu, khususnya di wilayah budaya Sunda. Hal ini dapat dilihat dari fungsi dan kegunaannya. Angklung sebagai bagian dari aktivitas masyarakatnya, terutama oleh kalangan masyarakat adat yang masih menjalankan tradisi agraris secara tradisional. Seperti dijelaskan oleh Budi, bahwa kehadiran musik bambu dalam kehidupan masyarakat budaya Sunda hadir sejak masyarakatnya menjalankan budaya agraris tradisional (D. S. U. Budi, Soedarsono, Haryono, \& Narawati, 2014: 139).

Berdasarkan hasil pengamatan dapat diyakini bahwa angklung sudah ada di dalam wilayah budaya Sunda jauh sebelum Hindu masuk ke Indonesia, pada masa masyarakat Sunda masih memegang Sunda Wiwitan sebagai ageman hirup hurip-nya, pada masa kehidupan masyarakatnya masih ngahuma atau bercocok tanam padi kering dengan cara berpindah-pindah.

Pola tanam padi kering dan pola tanam padi basah di sawah selalu menghadirkan angklung dalam siklus kehidupan masyarakat agraris tradisional. Sebagian pengamat budaya mendeskripsikan angklung merupakan salah satu kelengkapan upacara ritual penanaman padi. Di wilayah Banten Kidul sebagai salah satu subkultur budaya Sunda yang lebih dikenal dengan masyarakat Kasepuhan Adat Banten Kidul, kedua pola tanam ini masih sangat setia dan ketat dijalankan oleh masyarakatnya. Angklung merupakan salah satu peralatan upacara ritual yang wajib dihadirkan dalam siklus penanaman padi, bahkan siklus kehidupan masyarakatnya.
Seni angklung tersebar di dalam wilayah budaya Sunda yang secara politis masuk ke beberapa wilayah, yaitu di Provinsi Jawa Barat, Provinsi Banten, dan Provinsi Jawa Tengah. Alat musik angklung tersebar di ketiga wilayah tersebut dalam berbagai penamaan sesuai dengan latar belakang sejarah serta kepercayaan masyarakat setempat sebagai kekayaan khasanah budayanya. Selain ketiga wilayah tersebut, seni angklung juga berkembang di Bali (Gold, 2016: 186; McGraw \& Sudarta, 2017: 170).

Khasanah seni music bambu yang mempergunakan kata angklung sebagai penamaannya tersebar di wilayah budaya Sunda di antaranya angklung Baduy, angklung Dogdog Lojor, angklung Buncis, angklung Gubrag, angklung Badeng, angklung Bungko, dan sebagainya. Selain itu masih banyak juga seni pertunjukan tradisional yang mempergunakan alat musik angklung, tetapi tidak memakainya sebagai nama jenis keseniannya yang dominan berfungsi sebagai 'pelengkap' upacara ritul.

Angklung dikenal sebagai sebuah alat musik individual yang secara teknis dianggap paling mudah untuk dimainkan, karena hanya diperlukan cara menggoyangkan atau menggetarkan saja untuk memainkannya. Sangat berbeda dengan alat musik konvensional lainya, seperti gitar atau piano, yang secara teknis memiliki tingkat kesulitan tersendiri. Secara teknis, memainkan alat musik angklung tidaklah serumit alat-alat musik tersebut. Namun dalam perkembangan selanjutnya, muncul pula upaya pengembangan dalam hal teknis memainkannya atau memodifikasi alat-alat musik angklung, termasuk dengan memberikan identitas atau penamaan terhadap alat musik angklungnya sebagai upaya kreatif para seniman atau pegiat angklung itu sendiri, di antaranya muncul penamaan angklung Padaeng sebagai hasil modifikasi Daeng Soetigna; angklung piano karya Yulius Abiyasa (Bandung), Koko Koswara (Sumedang), dan Mang Koko (Tasikmalaya); klungbot (angklung robot) karya Eko Mursito, beberapa versi inovasi angklung toél karya Yayan Udjo; dan sebagainya.

Antara tahun 1897-1900, beberapa puluh tahun sebelum Daeng Soetigna melakukan modifikasi terhadap angklung, John Calhoun Dea- 
gan, salah seorang musisi dengan bayaran paling mahal di Amerika saat itu, guru musik, arranger, dan juga dikenal sebagai pengusaha alat musik telah melakukan modifikasi terhadap angklung. Deagan memodifikasi angklung setelah dia melihat angklung buncis yang dibawa oleh sindikat perdagangan pada masa penjajahan Belanda yang dipertunjukkan dalam rangkaian kegiatan Chicago World Festival tahun 1897. Upaya modifikasi yang dilakukan oleh Deagen adalah membuat angklung dengan bahan yang berbeda. Deagan mempergunakan bahan berupa tabung alumunium yang ditata ke dalam tangga nada diatonis-kromatis. Selanjutnya alat musik tersebut diberi nama Deagan Organ Chime's. Alat musik ini sudah dipatenkan tanggal 6 Maret 1900 (Hopkin, 1993).

\section{Angklung di Sunda}

Di dalam sejarah musik Barat, setiap era memiliki sejumlah ciri yang unik yang menandakan secara jelas era tersebut. Salah satu ciri yang unik tersebut di antaranya dapat berbentuk alat musik (Martiana, 2015: 406). Hal ini pun terjadi di dalam budaya Sunda. Angklung merupakan alat musik yang memiliki bentuk dan keunikan tersendiri.

Dilihat dari bentuk serta kapasitasnya sebagai alat musik, angklung merupakan salah satu alat musik yang pada proses pembuatannya merupakan hasil kecerdasan dan sentuhan kreatif. Dalam hal ini, kecerdasan, teknologi, serta tingkat kreativitas para nenek moyang sangatlah luar biasa. Hal ini terbukti dari berbagai variasi bentuk alat musik tersebut. Angklung merupakan salah satu bentuk alat musik hasil kreativitas individu pembuatnya, terlepas dari latar belakang kepercayaan mereka. Yang jelas, tingkat kreativitas para pembuat angklung dengan memberdayakan hasil alam di sekitarnya dilengkapi ilmu pengetahuan dan teknologi dapat menghasilkan peralatan yang luar biasa dan sangat bermanfaat bagi umat manusia.

Berangkat dari fenomena tersebut, upaya pengembangan atau modifikasi pada alat-alat musik pun sangat menarik untuk dicermati. Berbagai upaya kreatif dalam rangka pengembangan khasanah alat musik dunia telah banyak dikaji dalam berbagai disiplin, bukan hanya dari segi disiplin musik saja, melainkan juga dari disiplin lain. Upaya-upaya modifikasi sebagai langkah pengembangan dan dalam rangka penyempurnaan, baik fisik, teknis, maupun garapan atau kemasan pertunjukannya telah banyak dilakukan para ahli atau praktisi musik.

Permasalahan yang berkaitan dengan angklung dapat dikatakan berasal dari hulu ke hilir. Dilihat dari kebutuhan bahan pembuatan angklung, yaitu bambu memiliki persoalan tersendiri, demikian juga setelah bambu tersebut menjadi sebuah alat musik. Upaya-upaya modifikasi angklung ini sudah banyak dilakukan.

\section{Angklung Padaeng}

Dalam pengembangan angklung, kreativitas Daeng Soetigna sejak sekitar tahun 1930-an turut memberikan warna baru bagi seni pertunjukan, khususnya pada perkembangan angklung. Pengembangan awal yang dilakukan Daeng Soetigna adalah dengan cara memodifikasi angklung sebagai salah satu alat bantu atau alat peraga dalam pendidikan musik supaya disenangi murid (Sumarsono, 2007: 103). Upaya yang dilakukannya turut memotivasi serta menambah daya tarik pembelajaran para anak didiknya.

Kreativitas yang dilakukan Daeng adalah menambah tangga nada alat musik angklung tradisional yang tadinya dominan bertangga nada salendro ditambah dengan angklung yang bertangga nada diatonis (7 nada). Pada tahapan selanjutnya Daeng memodifikasi angklung diatonis yang tadinya hanya tujuh nada dengan menambah beberapa nada sisipan sehingga

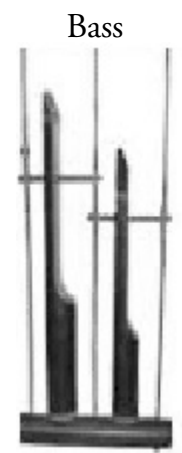

2 Tubes

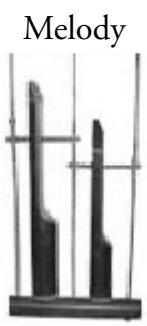

2 Tubes

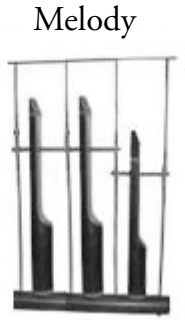

3 Tubes

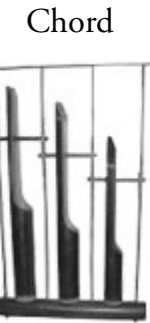

3 Tubes
Gambar 1. Angklung modifikasi Daeng Soetigna. (http://malvanabilla.blogspot.co.id/2014/03) 
tangga nada angklung yang dihasilkan menjadi diatonis kromatis (12 nada). Selain menambah tangga nada diatonis-kromatis pada angklung, Daeng juga melakukan modifikasi dengan membentuk sekelompok alat musik angklung untuk keperluan orkes atau ensambel musik angklung untuk keperluan permainan bersama (Wiramihardja \& Setiana, 1975: 10).

Angklung tujuh nada dikenal dengan nama angklung sarinande, istilah untuk angklung Padaeng yang hanya menggunakan nada dasar C tanpa nada kromatis. Terdapat dua unit angklung sarinande, yaitu angklung unit kecil yang berisi 8 angklung (dari nada do rendah sampai do tinggi) dan angklung sarinande plus

Tabel 1. Kombinasi nada akompanion mayor.

\begin{tabular}{lccccc}
\hline \multirow{2}{*}{ No Nada Mayor } & \multicolumn{5}{c}{ Nada Tabung Suara } \\
\cline { 3 - 6 } & 1 & 2 & 3 & 4 \\
\hline 1. & C7 & C & ais & g & E \\
2. & C\#7 & Cis & b & gis & F \\
3. & D7 & D & c & a & Fis \\
4. & C7 & Cis & ais & g & Dis \\
5. & E7 & D & b & gis & E \\
6. & F7 & Dis & c & a & F \\
7. & F\#7 & E & cis & ais & Fis \\
8. & G7 & B & g & f & D \\
9. & A 7 & C & gis & fis & Dis \\
10. & A7 & Cis & a & g & E \\
11. & B 7 & D & ais & gis & F \\
12. & B7 & Dis & b & a & Fis \\
\hline
\end{tabular}

Sumber: http://klungbot.com/kajian-variasi-angklung

terdiri dari 13 buah angklung (dari nada sol rendah hingga mi tinggi).

Angklung tersebut oleh Daeng dimodifikasi kembali didasarkan pada bentuk serta fungsinya secara musikal. Hasil modifikasi ini selanjutnya dibagi menjadi beberapa kelompok, yaitu angklung melodi, angklung bas, angklung kord, dan angklung akompanimen. Bentuk angklung melodi terdiri dari dua tabung (besar dan kecil) dalam satu ancak (rangka)-nya. Tabung besar untuk bunyi nada pokok sedang tabung yang kecil merupakan bunyi nada satu oktaf yang difungsikan untuk memperkuat bunyi yang dihasilkan (Hartanti \& Astuti, 2016: 122-123). Angklung melodi ini disusun berdasarkan pada

Tabel 2. Kombinasi nada akompanion minor.

\begin{tabular}{|c|c|c|c|c|}
\hline \multirow{2}{*}{\multicolumn{2}{|c|}{ No Nada Minor }} & \multicolumn{3}{|c|}{ Nada Tabung Suara } \\
\hline & & \multirow{2}{*}{$\frac{1}{\mathrm{C}}$} & \multirow{2}{*}{$\begin{array}{l}2 \\
\mathrm{~g}\end{array}$} & \multirow{2}{*}{$\frac{3}{\text { es }}$} \\
\hline 1. & $\mathrm{Cm}$ & & & \\
\hline 2. & $\mathrm{C} \# \mathrm{~m}$ & Cis & gis & $\mathrm{e}$ \\
\hline 3. & $\mathrm{Dm}$ & G & $\mathrm{a}$ & $\mathrm{f}$ \\
\hline 4. & $E^{b} m$ & As & ges & es \\
\hline 5. & $\mathrm{Em}$ & $\mathrm{B}$ & $\mathrm{g}$ & $\mathrm{e}$ \\
\hline 6. & $\mathrm{Fm}$ & $\mathrm{C}$ & $\mathrm{a}$ & $\mathrm{f}$ \\
\hline 7. & $\mathrm{~F} \# \mathrm{~m}$ & Cis & $\mathrm{a}$ & fis \\
\hline 8. & $\mathrm{Gm}$ & $\mathrm{D}$ & bes & $\mathrm{g}$ \\
\hline 9. & $A^{b} m$ & $\mathrm{~B}$ & as & es \\
\hline 10. & $\mathrm{Am}$ & $\mathrm{C}$ & $\mathrm{a}$ & e \\
\hline 11. & $\mathrm{~B}^{\mathrm{b}} \mathrm{m}$ & Bes & ges & es \\
\hline 12. & $\mathrm{Bm}$ & $\mathrm{D}$ & $\mathrm{b}$ & fis \\
\hline
\end{tabular}

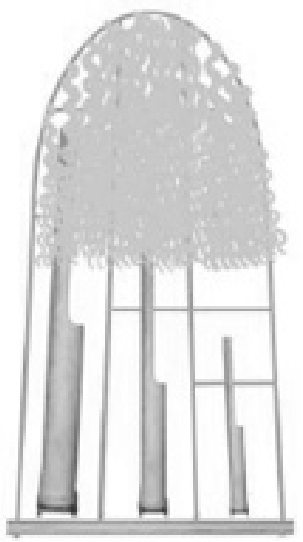

Angklung Dogdog Lojor

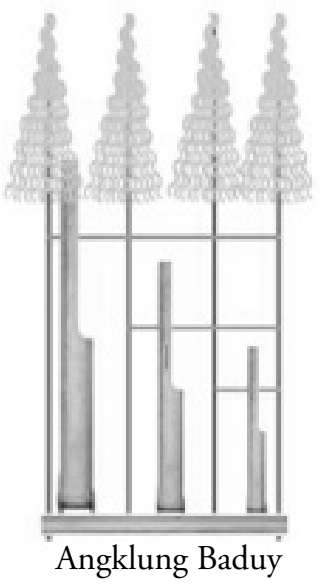

Gambar 2. Perbandingan bentuk angklung. (Budi, 2016: 180)

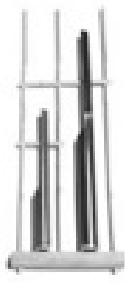

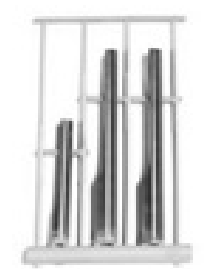
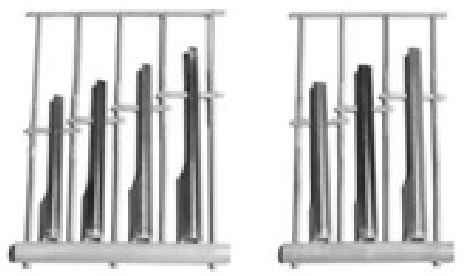

Angklung Padaeng 
urutan nada-nada yang ada pada tuts piano dengan menggunakan angka dari nomor 0 hingga nomor 30 dan menggunakan huruf dari huruf F hingga G sebagai kodifikasinya. Daeng sendiri menamakan pembagian angklung melodi ini dengan 0-30 sebagai angklung melodi biasa, sedangkan angklung dari $F$ hingga $G$ sebagai angklung melodi bass/besar (Wiramihardja \& Setiana, 1975: 12-19). Apabila dilihat dari penamaannya, angklung melodi dalam ansambelnya digunakan untuk membentuk melodi dari setiap lagu yang akan disajikan, disesuaikan dengan jumlah nada yang dimainkan dalam setiap lagunya.

Dalam sebuah catatan manuskrip yang ditulis oleh Daeng Soetigna diungkapkan bahwa suara dan kualitas angklung-angklung telah diperiksa dengan teliti. Tinggi nada selaras dengan peraturan internasional yang resmi: $\mathrm{a}^{\prime}=$ 440 (Hz.)”. Dalam hal ini, semua nada angklung Padaeng distandarkan sesuai dengan ilmu musik barat.

Daeng menjelaskan cara memainkan angklung melodi sebagai alat untuk pembelajaran musik. Posisi tabung besar ditempatkan di sebelah kanan, sedangkan posisi tabung kecil di sebelah kiri. Posisi tangan kiri memegang bagian silang tiang tengah, sedangkan posisi tangan kanan memegang bagian dudukan soko atau ujung sudut kanan bawah tabung dengan cara menggerakkan atau membunyikan tangan kanan ke kiri dan ke kanan (Manuskrip No.5 Koleksi Handiman). Di dalam memainkan angklung Padaeng, paling tidak terdapat tiga teknik dasar cara memainkan yaitu digetarkan (kurulung), disentakkan (centok), dan digetarkan dengan menahan salah satu tabung suara (tengkep).

Langkah-langkah yang sudah banyak dilakukan oleh para kreator atau para perajin angklung dalam rangka upaya pengembangan terhadap alat musik angklung lainnya adalah upaya mengeksplorasi bahan pembuatan angklung untuk memperoleh kemungkinan-kemungkinan lain. Ini dilakukan karena bahan bambu untuk pembuatan angklung sudah semakin berkurang, bahkan mulai sulit diperoleh. Selain jumlah perkebunan atau hutan bambu semakin berkurang, juga adanya produk mebel atau bahan kerajinan lain yang juga sama-sama mempergunakan bambu sebagai bahan bakunya.

Dilihat dari perkembangan bentuknya, angklung Padaeng dapat dikatakan lebih sederhana dibandingkan dengan angklungangklung tradisional. Dibandingkan dengan angklung tradisional, ornamen angklung Padaeng lebih sederhana. Pada angklung tradisional terdapat ornamentasi, hiasan, atau aksesoris yang memiliki makna-makna tertentu. Ornamen, hiasan, atau asesoris tidak terdapat pada angklung Padaeng (Gambar 2). Ini desebabkan karena angklung Padaeng dimaksudkan sebagai alat peraga untuk kepentingan dunia pendidikan seni musik yang lebih mengedepankan kebersaman, kedisiplinan, kesetaraan, dan gotong royong, sama sekali tidak memunculkan masalah makna dan estetika visual.

\section{Angklung 'Pukul'}

Hingga saat ini belum ada terminologi yang tepat untuk menamai angklung yang dimaksud di sini. Saya menggunakan istilah angklung pukul karena cara memainkannya dengan cara dipukul (Gambar 3). Angklung ini dianggap sebagai tonggak munculnya angklung pukul lainnya. Angklung pukul ini dirancang oleh seorang berkebangsaan Perancis yang bernama Georg Wiesmann pada tahun 1984 setelah dia mendapatkan angklung tersebut dari ayahnya. Dalam perkembangan selanjutnya Wiesmann merancang angklung tersebut supaya bisa dimainkan secara duet atau berpasangan.

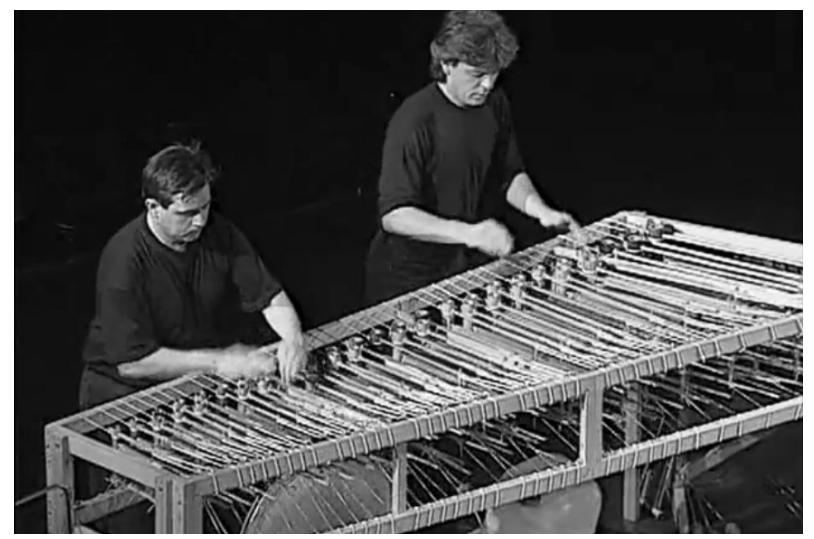

Gambar 3. Angklung 'pukul' group Angklung Duo. (Sumber: https://www.youtube.com/watch?v=) 


\section{Angklung Toel}

Pengembangan teknik memainkan angklung sudah dilakukan oleh beberapa pegiat, pelaku, atau inovatornya. Teknik memainkan alat musik angklung pun sudah banyak dilakukan. Salah satu yang cukup fenomenal adalah munculnya angklung Toel sebagai karya modifikasi salah seorang anak dari Udjo Ngalagena, yaitu Yayan Udjo. Udjo Ngalagena sendiri merupakan pelestari dan pegiat kesenian angklung. Melalui Saung Angklung Udjo, ia mengembangkan berbagai program kegiatan dan fasilitas yang menunjang pengembangan minat masyarakat terhadap angklung (Masunah, 2012: 1; Rahmi, 2016: 1038; Juandi, Andari, \& Setiyorini, 2018: 1-2). Modifikasi yang dilakukannya adalah menjadikan angklung dapat dimainkan secara solo atau mandiri.

Apabila dilihat dari sejarahnya, sebuah alat musik angklung biasa dimainkan oleh satu orang saja. Jadi dari sejumlah alat musik angklung, baik angklung tradisional maupun angklung Padaeng akan sebanding dengan jumlah orang yang memainkannya, ditambah dengan sejumlah pemain pendukung lain yang memainkan alat musik selain insrumen angklung.

Satu set angklung Toel dibentuk dari sebuah rangka kayu atau besi yang mewadahi 30 angklung dari nada G3 - C6. Angklung dipasang berjejer dalam 2 baris. Baris yang di bawah yang lebih dekat dengan badan pemain terdiri dari nada-nada penuh (G, A, B, C, dan seterusnya, sementara pada sap bagian atas terdiri dari nada-nada kromatis (G\#, A\#, C\#, dst).

Setiap angklung sengaja dipasang dengan cara terbalik, karena bagian tabung dudukan soko atau tabung dasar merupakan bagian paling penting dalam mendapatkan bunyi, di mana pada dudukan soko ini tabung angklung dibenturkan untuk mendapatkan bunyi. Di bagian paling bawah, 'topi' angklung diikatkan pada sebuah palang yang dipasang miring mengikuti ukuran panjang setiap angklung dengan kawat. Sementara itu di bagian atas, tabung dudukan soko angklung diikat menggunakan tali elastis pada palang mendatar. Tali elastis ini digunakan agar setiap angklung yang sudah dibunyikan akan kembali pada posisi semula.

Pada awalnya, angklung Toel hanya mempergunakan karet gelang yang diuntai secara bersambung, tetapi dalam perkembangan selanjutnya didapatkan sebuah tali elastis karet hitam yang dibalut dengan benang dan dianggap tali elastis yang lebih baik dibanding karet gelang. Dalam pandangan Yayan Udjo, tali elastis ini merupakan bagian yang paling penting dan belum tergantikan dalam konstruksi angklung Toel hingga diperoleh tali dari bahan yang dianggap lebih baik (Gambar 4).

Pada bagian lain, khususnya pada tabung dudukan soko ini dipasang pasak bulat yang dibuat dari kayu yang panjangnya kurang lebih lima sentimeter $(5 \mathrm{~cm})$. Posisi pasak kayu ini dipasang di bagian atas dari ujung tiang atau bingkai angklung yang dipasang menembus tabung dudukan soko dengan posisi pemasangan mendekati badan pemain, agar proses membunyikan angklung menjadi lebih mudah terjangkau. Teknik memainkan atau membunyikan angklung Toel adalah pada saat pasak tersebut di-toel (ditepak atau ditarik sedikit, kemudian dilepas), maka tabung angklung akan bergetar beberapa kali mengikuti daya tarik tali elastis tesebut. Teknik selanjutnya adalah menggetarkan pasak kayu tadi, terutama

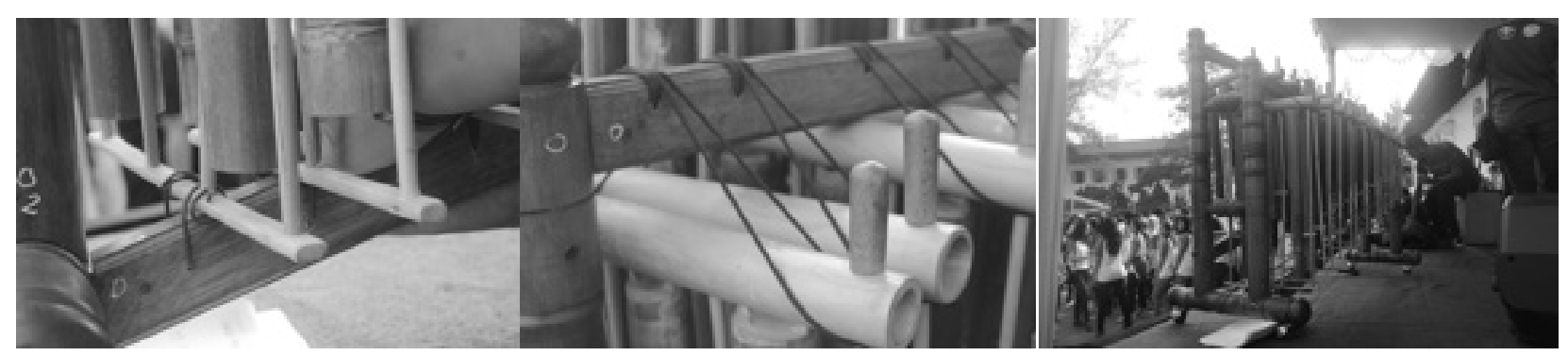

Gambar 4. Angklung Toel. (Dokumentasi: Budi, 2015) 
untuk bunyi kurulung. Untuk teknik dicentok, atau stakato agak sulit dilakukan atau memiliki kesulitan tersendiri karena pemain tidak dapat menengkep (mematikan bunyi) tabung angklung supaya tidak berbunyi.

Apabila teknik membunyikan atau memainkan angklung Toel ini sudah dipahami, maka seorang pemain angklung dapat menggunakan kedua belah tangannya secara bergantian memainkan angklung Toel. Secara teknis, angklung Toel bagi para pemainnya memiliki kelebihan dan kekurangan. Salah satu kekurangannya adalah angklung Toel tidak dapat memainkan nada akor atau lebih dari dua nada karena keterbatasan jumlah tangan yang hanya sepasang. Selain itu juga menjadi kekurangan lainnya karena ketika bermain dalam kecepatan atau tempo tinggi bunyi getaran angklung sebagai artikulasi bunyi yang menjadi ciri khas alat musik angklung menjadi tidak jelas. Kelebihan angklung Toel adalah setiap pemain pada saat memainkan angklung dapat dilakukan dalam tempo cepat. Berdasarkan hasil eksplorasinya, Yayan Mulyana paling tidak sudah memodifikasi sebanyak delapan rancangan angklung Toel.

\section{Angklung Robot (Klungbot)}

Angklung robot (klungbot) merupakan hasil modifikasi Eko Mursito, salah seorang dosen Teknik Fisika ITB, Teknisi Laboratorium Fisika, mahasiswa, serta dosen dari Institut Teknologi Bandung (ITB). Ide dasar terciptanya klungbot ini didasarkan pada pertanyaaan, dapatkah suatu robot memainkan seperangkat angklung untuk mempertunjukkan sebuah lagu yang kompleks laiknya sebuah grup musik manusia?

Atas dasar itulah angklung robot dibuat. Robot angklung ini berupa perangkat mikroprosesor yang dilengkapi dengan banyak motor serta lengan-lengan mekanis. Satu robot memiliki 12 lengan, cukup untuk memegang set angklung satu oktaf. Dengan demikian, diperlukan tiga buah robot untuk unit angklung tiga oktaf. Angklung robot tersebut dapat dijalankan melalui bahasa pemrogram berbasis Java Script yang dioperasikan melalui sebuah
PC atau laptop. Angklung robot dapat bermain laiknya seorang pemain angklung professional (E. M. Budi, Rochim, Dipojono, Handojo, \& Sarwono, 2013). Angklung dibunyikan sesuai dengan perintah konduktor yang diwakili oleh program. Isi program itu berupa notasi dari partitur asli lagu-lagu yang diinginkan penggunanya.

Dalam proses pembuatannya, angklung robot yang dikembangkan oleh Eko Mursito Budi dan kawan-kawan di Teknik Fisika ITB dibentuk oleh tiga kelompok. Kelompok hardware (perangkat keras) yang menggarap

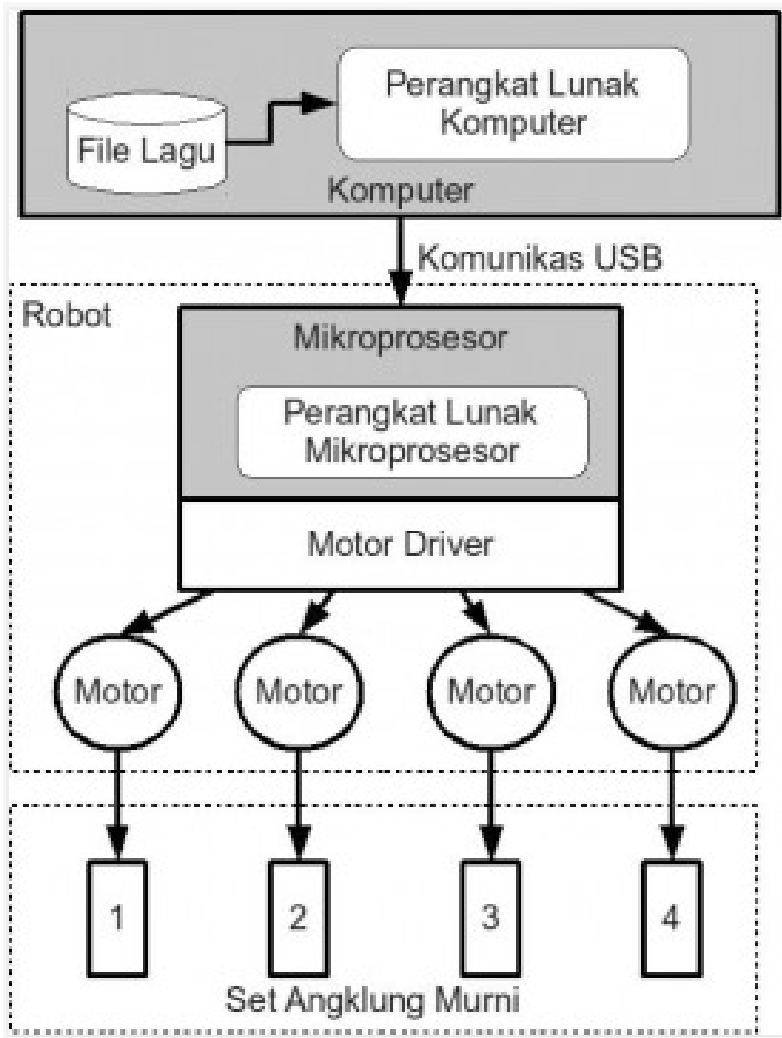

Gambar 5. Salah satu versi dari fitur mekanisme angklung robot. (http://klungbot.com/fitur-dan-fungsi-klungbot)

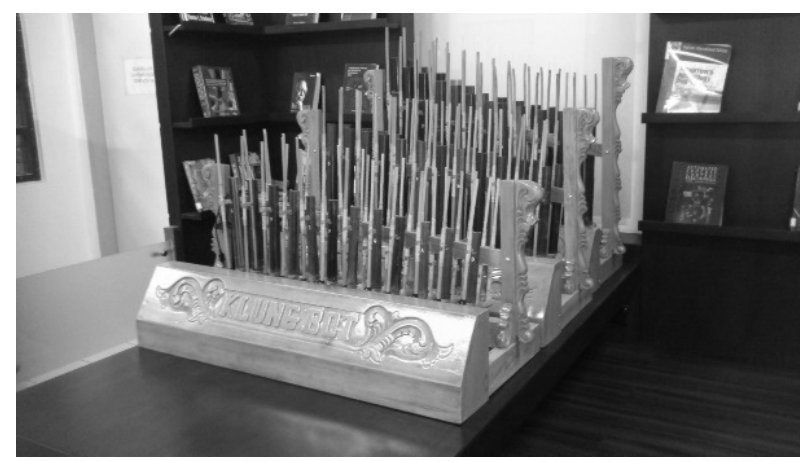

Gambar 6. Salah satu bentuk Klungbot (Angklung Robot) (Sumber:http://klungbot.com/category/instrumen/page/2) 
pembuatan lengan-lengan robot dibantu oleh Sutriana, Sholeh Taryana, dan Bolo. Sementara itu software (perangkat lunak) yang menyusun pemrograman komputer dirancang oleh Fariza Dian Prasetyo dan Alvin Nurhadi, sedangkan pembuatan alat musik angklungnya sendiri dibuat oleh Kang Sunata, perajin angklung dari Padasuka Bandung (http://klungbot.com/ klungbot-angklung-robot/\#comment-26).

Secara teknis, angklung robot dapat dimainkan dengan dua cara, yaitu secara manual dan otomatis. Secara manual, si pemain dapat mengoperasikan angklung dengan mengklik keyboard pada layar komputer yang dirancang khusus mirip seperti halnya tuts piano. Selain itu, si pemain angklung robot sebelumnya dapat menulis suatu aransemen lagu dalam bentuk notasi angka. Notasi-notasi lagu yang sudah ditulis akan muncul di playlist, dan not-not inilah yang kemudian dibaca oleh PC untuk menjalankan angklung robot secara otomatis. Dalam perkembangan selanjutnya, Eko Mursito Budi pun sudah berhasil memodifikasi angklung robot-angklung robot yang dirancangnya, di samping para inovator angklung robot lainnya yang berasal dari luar lembaga ITB. Bahkan dalam perkembangan berikutnya, mulai dirancang prototype sistem aplikasi multimedia dalam memainkan angklung pada android (Mayatopani \& Fahriansyah, 2017: 30; Rizki \& Handoko, 2017: 17; Daeanza, Nurhayati, \& Eridani, 2017: 38-40).

\section{Modifikasi Angklung}

Seperti sudah diutarakan pada bagian sebelumya, angklung Padaeng secara fungsi dan kegunaannya adalah untuk kepentingan alat bantu atau alat peraga bagi pendidikan seni musik. Angklung Padaeng dibuat agar semua murid senang belajar musik serta mengakomodasi semuanya agar terlibat langsung secara aktif (Sumarsono, 2007: 102). Hasil dari pendidikan musik yang ditanamkan oleh Daeng selanjutnya diteruskan oleh murid-muridnya, terutama adalah nilai kedisiplinan, kesetaraan, dan kebersamaan. Kemasan pertunjukan musik yang menjadi ciri khas dari angklung Padaeng adalah dibentuk menyerupai pertunjukan paduan suara. Pertunjukan dipimpin oleh seorang konduktor atau dirigen melalui gerakan-gerakan kedua tangannya sesuai dengan birama lagu yang dimainkan angklung.

Hal lain yang paling menarik dari berbagai upaya memodifikasi alat musik angklung yang telah dilakukan Daeng Soetigna, Eko Mursito Budi, dan Yayan Mulyana adalah terdapat perbedaan dalam hal penempatan atau pemasangan alat musik, meskipun secara bentuk ketiga insrumen hasil modifikasi tersebut tetap memiliki kesamaan (Gambar 7). Posisi alat musik angklung Padaeng dan angklung robot karya Eko Mursito pada saat dibunyikan, apabila dilihat dari teknik permainan secara konvensional, tidak banyak berbeda dengan angklung-angklung tradisional. Dalam hal ini, posisi alat musik di sini adalah secara struktur posisi alat musik angklung dimainkan dalam posisi berdiri. Bagian dudukan soko (dasar) tabung angklung yang merupakan bagian (tempat) benturan tabung suara berada di bagian bawah, dan posisi tabung suaranya pun berdiri, tidak terdapat rekayasa teknis lain terhadap alat musik angklung tersebut. Pada kasus angklung 'pukul', posisi alat musik angklung dipasang dengan cara 'ditidurkan'. Posisi dudukan soko (dasar) dipasang lebih dekat

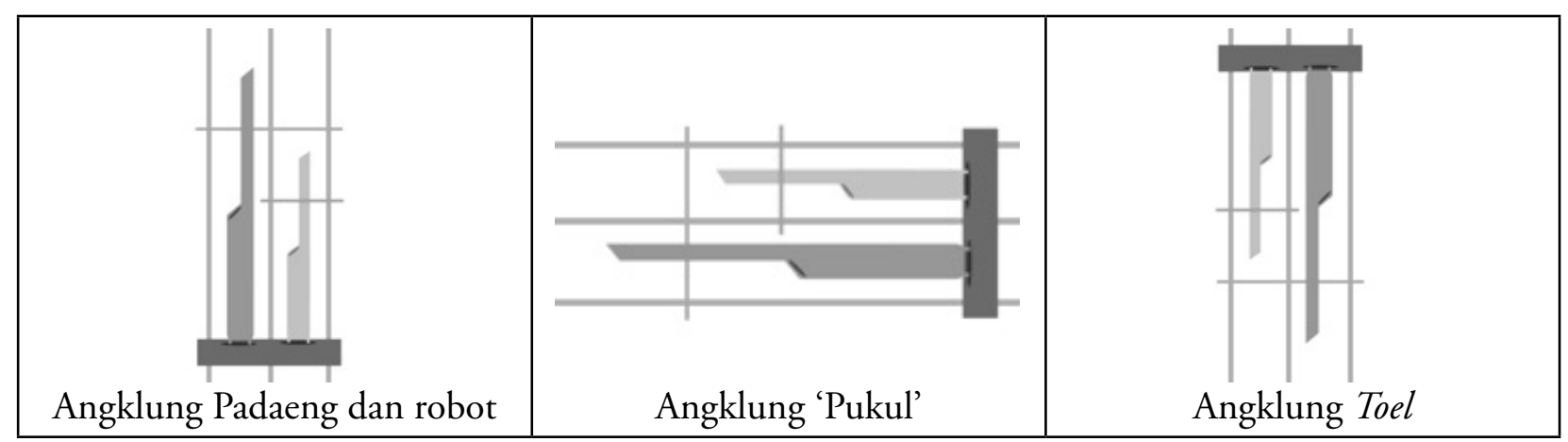

Gambar 7. Posisi pemasangan angklung. 
dengan pemain angklung. Berbeda dengan struktur alat musik angklung Toel yang dimodifikasi oleh Yayan Mulyana. Posisi alat musik angklung oleh Yayan Mulyana dipasang secara terbalik, karena penempatan bagian dudukan soko (dasar) tabung angklung sengaja dipasang terbalik atau menjadi di bagian atas, sesuai dengan rancangan atau konsep yan dibuatnya.

\section{Penutup}

Alat musik angklung masih memerlukan ide-ide dan upaya-upaya modifikasi agar berbagai hal yang berkaitan dengan kelemahan-kelemahan teknis yang dirasakan oleh para pemainnya dapat diatasi, sehingga alat musik angklung dapat semakin baik. Ide-ide dan upaya-upaya modifikasi ini perlu mendapat dukungan dari berbagai pihak, perajin, para komposer atau penata musik, para musisi, dan sebagainya. Upaya-upaya modifikasi terhadap alat musik angklung secara organologi yang dilakukan oleh Daeng Soetigna (angklung Padaeng), Eko Mursito Budi (angklung Robot), dan Yayan Mulyana (angklung Toel) bukanlah akhir dari langkah pengembangan seni musik. Upaya yang telah mereka lakukan baru dikategorikan sebagai upaya termutakhir dilihat dari teknik memainkan, yang tidak terlepas dari masih adanya kekurangan.

Upaya modifikasi yang masih perlu juga dilakukan adalah masalah yang berhubungan dengan bambu sebagai bahan utama pembuatan angklung. Penyiapan atau hingga proses pengolahan bambu untuk bahan pembuatan alat musik angklung pun perlu diperbaharui, berkaitan dengan daya tahan alat musik angklung selalu menjadi masalah utama, yakni ketika alat musik angklung lebih cepat rusak, hanya dapat bertahan tidak lebih dari 3-5 tahun yang disebabkan serangga.

\section{Kepustakaan}

Budi, D. S. U., Soedarsono, R. M., Haryono, T., \& Narawati, T. (2014). Angklung Dogdog Lojor pada Upacara Seren Taun. Resital: Jurnal Seni Pertunjukan, 15(2), 139-151. Retrieved from http://www.journal.isi.ac.id/index.php/ resital/article/view/848
Budi, E. M., Rochim, A. A., Dipojono, H. K., Handojo, A., \& Sarwono, J. (2013). Musical gesture recognition for interactive angklung robot. Proceedings of 2013 3rd International Conference on Instrumentation, Control and Automation, ICA 2013, 149-154. https:// doi.org/10.1109/ICA.2013.6734062

Daeanza, D. M., Nurhayati, O. D., \& Eridani, D. (2017). Aplikasi Simulasi dan Main Angklung (Saung) Berbasis Android. Jurnal Teknologi Dan Sistem Komputer, 5(1), 37. https://doi. org/10.14710/jtsiskom.5.1.2017.37-42

Gold, L. (2016). Bali 1928, Volume 1: Gamelan Gong Kebyar Music from Belaluan, Pangkung, Busungbiu-the Oldest New Music from Bali. Asian Music, 47(2), 179-188.

Halliburton, M., \& Aragon, L. V. (2012). Copyrighting Culture for the Nation? Intangible Property Nationalism and the Regional Arts of Indonesia. International Journal of Cultural Property, 19(3), 269-312. https://doi.org/http://dx.doi.org/10.1017/ S0940739112000203

Hartanti, R. S., \& Astuti, B. (2016). Analysis of Angklung Sound Intensity as a Acoustic Instrument. Natural Sciences and Mathematics Research, 2(1), 122-126.

Hopkin, B. (1993). Deagan Organ Chimes. The Experimental Musical Instruments Journal. Retrieved from http://www.harmonize.com/ dapperdans/deagan_organ_chimes/deoc_ emi_article/deoc_emi_article.htm

Juandi, V. S., Andari, R., \& Setiyorini, H. P. D. (2018). The Influence of Sustainable Tourism Development towards Tourists' Satisfaction in Saung Angklung Udjo. IOP Conference Series: Earth and Environmental Science, 145(1). https://doi.org/10.1088/1755-1315/145/1/ 012020

Martiana, P. (2015). Dari Tari ke Musik: Pembentukan Musik Suita Pada Era Musik Barok. Panggung: Jurnal Seni Budaya, 25(4). Masunah, J. (2012). Pemuliaan Angklung melalui Model Desa Binaan Berbasis Wisata Seni dan Budaya. Panggung:Jurnal Seni Budaya, 22, $1-15$.

Mayatopani, H., Fahriansyah, E., \& Informatika, 
P. S. (n.d.). Perancangan Prototype Sistem Aplikasi Multimedia Dalam Memainkan Angklung Pada Platform Android, II(September 2017), 29-40.

Musthofa, B. M. (n.d.). Saung Angklung Udjo : Invensi Tradisi Lokal yang Mendunia, (2), 136-149.

Rahmi, M. (2016). Pengaruh Customer Experience terhadap Behavioral Intention Wisatawan di Saung Angklung Udjo (Survey Terhadap Wisatawan Nusantara yang Berkunjung ke Saung Angklung Udjo). Jurnal Manajemen Pemasaran, VI(2), 1033-1040.

Rizki, N. M., \& Handoko, S. (2017). Multi-Octave Orchestra Music Application of Angklung Based on Android Using Accelerometer Sensor, 15(1), 17-25.

Sumarsono, T. (2007). Membela kehormatan angklung: sebuah biografi dan bunga rampai Daeng Soetigna / disusun oleh Tatang Sumarsono, Erna Garnasih Pirous. (E. G. Pirous 1941-, Ed.). [Bandung]: Yayasan Serambi Pirous.

Wiramihardja, O. A. R., \& Setiana, A. (1975). Panduan bermain angklung. Jakarta: Pusat Penelitian dan Pengembangan Kebudayaan,
Badan Pengembangan Sumber Daya Kebudayaan dan Pariwisata, Kementerian Kebudayaan dan Pariwisata, 2011.

\section{Webtografi}

http://kbbi.web.id

http://klungbot.com

http://malvanabilla.blogspot.co.id/2014/03/alatmusik-angklung.html

http://www.bandungtourism.com/tododet. php?q=Angklung

https://www.youtube.com/watch?v=pz6SGrV64E

U\&index=1 \&list=RDpz6SGrV64EU

\section{Informan}

Udjang (56 tahun). Perajin Angklung di Padasuka Kota Bandung.

Handiman (79 tahun). Perajin Angklung yang merupakan murid dari Pa Daeng Sietigna. Jln. Surapati No. 95 Bandung 40123

Yayan Udjo (58 tahun). Kreator Angklung Toel; Anak tokoh angklung Udjo Ngalagena dari Saung Angklung Udjo. 